\title{
Editorial
}

\section{Sexual spin}

"'Scuse me", said the Elephant's Child most politely, "but have you seen such a thing as a Crocodile in these promiscuous parts?"

Rudyard Kipling Fust So Stories

The sexual health of adolescents in the Western world is generally declining. In the UK, which has the highest teenage conception rate in Western Europe, over 8000 girls under 16 years of age have unplanned pregnancies of which more than half end in abortions. ${ }^{1}$ The conception rate for 1996 was 9.4 conceptions per 1000 girls aged 13 to 15 , a rise of $11 \%$ on the previous year.

The USA had 15.3 million new cases of sexually transmitted infections (STIs) in 1996 with teenagers and young adults being the most affected groups. By the age of 24, one in three sexually active people in America has had an STI. ${ }^{2}$ UK doctors treat about 740000 new cases of STI every year, ${ }^{3}$ of which teenagers comprise the most at-risk age group. The number of chlamydia infections in girls aged 16 to 19 rose by $30 \%$ between 1996 and $1997 .^{4}$

The tragic legacy of teenage heartache, disillusionment and cynicism also has to be taken into account. Several studies have shown that up to $70 \%$ of girls who lost their virginity before 16 felt in retrospect that this was too early and expressed regret that they had not waited until they were older. ${ }^{5-7}$ Relatively little work has been done on the psychological impact of teenage sex, but sexually active teenagers appear at higher risk of depression and attempted suicide than their peers who retain their virginity. $^{89}$

Whilst the morbidity of teenage sex escalates upwards, average age of first intercourse continues to fall. Over the past 40 years, the median age of first intercourse in Britain has lowered by 4 years for women and 3 years for men. ${ }^{5}$ The pressures encouraging teenagers to have sex have probably never been greater. Cinema, television, pop music, videos, the Internet, CD-ROMs, novels and teen magazines unite in projecting sex as a 'must have' status symbol and the primary reason for living. Headlines such as "I think about sex every three minutes" and "Steamy sex test" make it clear that delaying sexual relationships is not high on their agenda. Even a sympathetic medical reviewer of teen magazines concludes, "Whether they are in a relationship or not, girls reading about boys' obsession with losing their virginity may continue to consider that sex is the 'price of going out with a boy". ${ }^{10}$

Our society, including the majority of doctors, has taken the line that teenage sex is inevitable and quite acceptable 'as long as you're in love'. A positive spin is usually applied to gloss over the harmful consequences of this approach. One eminent reviewer merely dismisses the current lack of success in achieving good sexual health as 'unfortunate' and predictably reiterates the standard 'solutions' of more sex education and increasing contraceptive provision. ${ }^{11}$ The evident failure of these measures is attributed to "attempts to withhold information on the basis of a particular agenda of family values and morality". ${ }^{11} \mathrm{~A}$ scan of any newsagent's shelves surely indicates that withholding information is not the problem!

Although increasing promotion of contraceptives intuitively seems a sensible move to reduce both unwanted pregnancies and STIs, the evidence put forward to support it often owes more to spin than substance. For example, the abstract of one recent American study declares that, in schools with a health resource centre (HRC) for health advice and condom distribution, "the proportion of students who had used a condom at last intercourse increased from $52-58 \%$; although the change was not statistically significant, it exceeded the increase in a group of comparison schools". ${ }^{12}$ What the abstract does not reveal is that condom use at last intercourse was higher to start with in control schools and also increased from 61.9 to $64.6 \%$ during the 3-year study period. Though the study shows that HRCs made no statistically significant difference in nearly all outcome measures, the authors report that "satisfaction with services was great".

Another study from Switzerland showed that over a 3-year campaign focusing on condom distribution, the percentage of 16-year-old girls who had had sexual intercourse increased from 36 to $57 \%$, while for boys the percentage increase was from 58 to $63 \% .{ }^{13}$ Though this trend did not reach statistical significance, the researchers nevertheless suggest that many of these girls would not have engaged in sexual intercourse without the condom distribution programme as "obviously purchasing condoms is easier than visiting a family planning center or a gynecologist." In spite of this disturbing admission, the authors proudly conclude that the programme should be maintained in the future, because it had a positive effect on the use of condoms. The study did not investigate the effect of the programme on unwanted pregnancies, which is a much more significant outcome measure than condom usage.

In 1995, data from the British national survey of sexual behaviour were used to examine the relation between the rates of condom use among teenagers and teenage conception rates during $1975-91 .^{14}$ They showed a strong positive relation between increasing use of condoms at first sexual intercourse and higher rates of teenage conceptions. This indicates that contraceptive failure is a major factor in teenage pregnancy, a finding supported by other studies. ${ }^{1516}$ This is due to the fact that condoms have a substantial failure rate, especially among inexperienced users. ${ }^{17}$ In my own practice, nearly all the unwanted pregnancies I see have resulted from contraceptive failure. In the rare instances where contraception has not been used, it is because the couple has been too intoxicated to do so, rather than to contraceptive unavailability.

In contrast to the lack of media coverage of the evidence on contraceptive failure, a few months earlier in 1995, the headlines were giving prolific positive spin on two studies on the effect of school sex education in the UK. "Lessons in saying 'no' help pupils to resist sex" and "Boys taught about sex at school stay virgins longer" were typical examples. The first study was again based on data from the national survey on sexual behaviour. It did indeed show that boys whose main source of sex education was schoolbased lessons were significantly more likely to remain virgins until the age of 16 than those who picked up their information on sex from their peers. ${ }^{18}$ However, it also 
showed that school-based sex education made absolutely no difference to the age of girls' first intercourse.

Furthermore, even though data on unplanned pregnancy rates and abortions were known, these were not published in the study in relation to the main source of sex education. The paper did report an increased likelihood of using some method of contraception during first intercourse among those for whom school was the main sex education source. This finding, however, as noted earlier, does not necessarily mean that there were fewer unwanted pregnancies and abortions in this group.

The second study demonstrated the effectiveness of a specific sex education programme in delaying first intercourse. ${ }^{19}$ The fact that the programmes used in the 25 control schools were totally ineffective was again ignored by the media. The conclusion that "sex education using an effective methodology can be associated with postponement of first intercourse" was universally interpreted by the press as "school sex education works". In fact, this study showed that in most cases it doesn't. There is, moreover, evidence from the USA that instruction about biological aspects of sex and contraception alone is associated with earlier first intercourse. ${ }^{20}$

It is vital to separate media spin from validated evidence of effectiveness. It is clear that early loss of virginity is associated with a wide range of other behaviours, including cigarette smoking, alcohol misuse, drug-taking, suspension from school, low self-esteem and suicide. ${ }^{8}$ Comprehensive attempts to improve adolescent sexual health will need a much broader agenda than sex education alone. Much teenage sexual activity has little to do with sex. ${ }^{21}$ It may be a way of expressing anger or frustration, a means of acting out, or a cry for attention..$^{22}$ It is frequently part of a search for love and meaning - neither of which are necessarily found in sex. Concentrating on preventing conception is treating a symptom rather than a cause; it does not address the issue of why teenagers are having early and unprotected sex.

There are several factors associated with a delay in age of first intercourse. These include high self-esteem, internal locus of control, good performance and motivation in edu-

1 Wise J. Teen pregnancies rise in England and Wales [news]. BMF 1998;316:882.

2 Tanne JH. US has epidemic of sexually transmitted diseases [news]. BMF 1998;317:1616.

3 Adler MW, ed. ABC of sexually transmitted diseases, 3rd edn. London: BMJ Adler MW, ed. A

Publishing, 1995. Office For Natio
HMSO, 1999

HMSO, 1999
Wellings K, Field J, Johnson AM, Wadsworth J. Sexual behaviour in Britain. London: Penguin, 1994

6 Curtis HA, Lawrence CJ, Tripp JH. Teenage sexual intercourse and pregnancy. Arch Dis Child 1988;63:373-9.

7 Dickson N, Paul C, Herbison P, Silva P. First sexual intercourse: age, coercion, and later regrets reported by birth cohort $B M \mathcal{F}$ 1998;316:29-33.

8 Orr DP, Beiter M, Ingersoll G. Premature sexual activity as an indicator of psychosocial risk. Pediatrics 1991;87:141-7.

9 Adcock AG, Nagy S, Simpson JA. Selected risk factors in adolescent suicide attempts. Adolescence 1991;26:817-28.

10 Mellanby A. Teen-zine sex is not all it seems. BMF 1996;312:451.

11 Adler $M$. Sexual health - a Health of the Nation failure. BMf 1997;314:1743-7.

12 Furstenberg, FF, Geitz LM, Teitler JO, Weiss CC. Does condom availability make a difference? An evaluation of Philadelphia's health resource centers. Fam Plan Persp 1997;29:123-7.

13 Hausser D, Michaud PA. Does a condom-promoting strategy (the Swiss STOP-AIDS Campaign) modify sexual behaviour? Pediatrics 1994;93:581-

14 Williams ES. Contraceptive failure may be a major factor in teenage pregnancy. BMF 1995;311:807. cation, having a father at home and having sex educational input from parents. ${ }^{23}$ Many, though not all, of these are potentially modifiable and it is a move in the right direction that many providers of sex education are beginning to realise that enabling parents to be more involved in sex education is preferable to professionals taking over this role completely.

Despite media accusations of shroud waving, health education campaigns based on 'fear appeals' which make their target audience feel susceptible to severe and damaging consequences are effective. ${ }^{24}$ This is partly because they break down false perceptions of invulnerability (which are particularly common in early adolescence ${ }^{25}$ ). They can also constitute a powerful motivation for behaviour change, provided that a clear and explicit message is given as to how the damaging consequences can be avoided. Over the past 20 years the primary message in sex education has been 'use contraception'. This approach has clearly failed and now the wisdom of targeting under-16-year-olds with it is at last being openly challenged. ${ }^{26}$ More recently, instruction in mutual masturbation and other alternatives to penetrative intercourse has been advocated as a preferred primary message. However, there is much which suggests that such techniques are unhelpful or even counter-productive in reducing teenage pregnancies and at least some STIs are likely to continue to be spread by such 'safe' sex practices. ${ }^{27}$

Media spin has caused teenage sexual health to skid dangerously off track and the casualty rates are increasing. Just as doctors who smoke should advise their patients not to do so on the basis of the overwhelming medical evidence that it causes harm, so should all healthcare professionals, irrespective of personal sexual experience, promote the message that it is medically unwise for individuals under the age of 17 to have sexual intercourse.

TREVOR STAMMERS

Tutor in General Practice, St George's Hospital Medical School, London, UK

Accepted 14 June 1999

Keywords: sex education

15 Pearson VAH, Owen MR, Phillips DR, Pereira Gray DJ, Marshall MN. Pregnant teenagers knowledge and use of emergency contraception. BMF 1995;310:1644.

16 Carnall D. Condom failure is in the increase [news] BMF 1996;312:1059.

17 Kirkman RJ User experience: Mates vs Nuforms $\mathrm{Br} \mathcal{F}$ Fam Plan 1990;15:107-11.

18 Wellings K, Wadsworth J, Johnson AM, Field J, Whitaker I, Field B. Provision of sex education and early sexual experience: the relation examined. BMF 1995;311:417-20.

19 Mellanby AR, Phelps FA, Crichton NJ, Tripp JH. School sex education: an experimental programme with educational and medical benefit. BMf 1995; 311:414-7.

$20 \mathrm{Ku} \mathrm{L}$, Sonenstien FL, Pleck JH. Factors influencing first intercourse in teenage men. Pub Health Rep 1993;108:681-94.

21 Genuis SJ, Genuis SK. The dilemma of adolescent sexuality. Part IV Dealing with the challenge. F Soc Obstet Gynecol Can 1994;16:1343-59.

22 Cohen MW. Adolescent sexual activity as an expression on nonsexual needs. Pediatr Ann 1995;24:324-9.

23 Kay L. Adolescent sexual intercourse; strategies for promoting abstinence in teens. Postgrad Med 1995;97:121-34.

24 Witte K. Preventing teen pregnancy through persuasive communications: realities, myths, and the hard-fact truths. F Commun Health 1997;22:137-54.

25 Biro FM, Rosenthal SL. Psychological sequelae of sexually transmitted diseases in adolescents. Obstet Gynecol Clin N Am 1992;19:209-17.

26 Genuis SJ, Genuis SK. Adolescent sexual involvement: time for primary prevention. Lancet 1995;345:240-1.

27 Genuis SJ, Genuis SK. Orgasms without organisms; science or propaganda? Clin Pediatr 1996;35:10-7. 